\title{
On the Construction of "Information Technology and Information Management” Network Course Platform
}

\author{
Dan Xu \\ School of Information and Engineering of Zhejiang Radio \& Television University, HangZhou, Zhejiang Province, China
}

\begin{abstract}
Education informatization is the trend of education development, also necessary for the development of the diversification of education. The construction of network curriculum is the effective carrier of information technology in Education. This paper carries on the preliminary ideas and explores the construction of the "information technology and information management" network course platform, and the network course platform building some of their design ideas. Further exploration to the network teaching of information technology era provides some clues and methods.
\end{abstract}

Index Terms - "Information technology and information management", Network course, Autonomous Learning, Personalized learning.

\section{Introduction}

The network curriculum, first it is a course. According to the dictionary, "the United States of America the new curriculum education encyclopedia entries said":"The course is generally refers to appear in the school teachers under the guidance of the learning activity, which contains the educational objectives, teaching content, teaching activities and evaluation methods of the broad concept"[1]. Network course compared to the original traditional courses need to take into account the education information dissemination way change, the idea of education, education mode, education methods of change, and the embodiment of the network teaching individuality, independence and interaction

Education informatization is the trend of education development, also necessary for the development of the diversification of education. Network course teaching as a new teaching theory and practice is an exploration of the education based on network environment. The construction of network curriculum is an effective platform of information technology in education. The construction of "information technology and information management" network course platform and implementation is the embodiment of educational informationization and a study on adaptation education diversified development. The construction of the platform to "information technology and information management" course is teaching with new ideas and space. It is the teaching profession new expansion. With the construction and implementation of the network course platform, and with the new ideas, new ideas and new methods in study of informationization teaching, we can perfect and improve the education pattern and the education processing at. Diversified forms to show the teaching meet the needs of the development of pluralistic society. In today's rapid development of the network information., it also needs to build the diversified show, interaction, at any time and in any place learning models in the field of education. This is also the purpose of this research.

\section{The Current Status of Web Based Course Construction}

Earlier development of network curriculum comes from abroad. Goldberg (Ginsburg, 1998), divided the network course. He thinks the network curriculum can be divided into three generations: The first generation is through the webpage providing teaching materials and other relevant information, and the connection with other relevant education network. The second generation is in addition to providing learning materials on the Internet, learners require bidirectional asynchronous communication via e-mail, electronic bulletin boards, online exercises and measurement. The third generation is in addition to the first generation, second generation, also called for the Internet chat room, conference calls, video conferencing or MUDS (MOOAs) simultaneous two-way communication system.

Points out at the Department of higher education of our country promulgated the "modern distance education system standard II trial standards" in V1.0 said that the network curriculum is the sum of "teaching content and implementation of a certain subject through the network performance of teaching activities" [2]. It consists of two parts: First, according to certain teaching objectives, the teaching content and the teaching strategies organized are supported by the network environment. Secondly, it reflects the "network" of the property. Network course take the Internet as a communication medium and show through the computer (mobile terminal). Therefore, the computer multimedia technology should be an important feature of network course. Common network chain, navigation, search, online registration and payment functions should be fully reflected. Massive Internet resources should be fully utilized in order to reflect the advantages of web-based courses. Again, the network curriculum should reflect the feature of network teaching. Characteristics of the network curriculum are the non-face-toface education. Both teaching and learning are separated in time and space.

\section{The Ubiquitous Problems of Network Course}

Application of the network course in the information platform, the current situation is uneven, some good and some bad. Especially in the construction of the network course, there still exist some problems. These problems are mainly manifested in the following aspects: 
1) At the technical level, current problems of network course server security and stability problems.

For the network course, the stability and security of network sometimes are the keys of technical problems. Due to the current network course based on communication hardware and software is not a standard, There Sites technical architecture and technical code of the rigorous problems. When the flow rate increased to a certain extent or hacking attack situation, the server will appear congestion and some unpredictable situation. .

2) Network education application history is too short to experience is limited, the educational circles of network technology and information propagation characteristics of master and not enough in-depth study. There are some networks courses only network courseware, or the material handling to the network. Focus on the presentation of teaching content; ignore the design of learning environment. Designing forms and teaching content is single, autonomous learning resources and navigation system is not strong. There also are the lack of evaluation and feedback, and the lack of teaching activities.

3) Without the traditional face-to-face teaching and students facing the situation difference between network learning .They always did not use the advantages of CAI technology. The students' progress is not enough to grasp. In the traditional teaching, the teacher will accord the student's response to adjust the teaching schedule. Sometimes a teacher may push on an in-depth explanation when the students did not understand the simple. But in the network teaching, if students facing is only a transition face stiff lectures, his inevitable problems are not solved in time, it would affect the continue(1) learning. it also dampened the enthusiasm of the students.

\section{The Preliminary Construction of" Information Technology and Information Management" Network Platform}

First, introduced the characteristics of the "information technology and information management" course: The curriculum system of the course is clear. The course covers a wide range, rich in content. And curriculum needs to develop a rich knowledge.

Because of the characteristics of the course, the network platform needs to consider students' autonomous learning and individualized learning. Need to give the students a lot of knowledge navigation in, also need to learn to inspire more.

Secondly, in the design of network course, there have the key technical problems to solve to the course of network teaching:

1) The system of database access in case of large capacity knowledgment

The content of the network course is huge and complicated. When it is in operation, it will inevitably encounter data access of large capacity. How to effectively manage and dispatch data is a key technical problem. Considering the large capacity of network course data access problem, you can use Microsoft SQL Server 2005 data platform. Microsoft SQL Server 2005 is a comprehensive database platform, .It uses integrated business intelligent tool for enterprise data management. It provides a more secure and reliable storage function of the database engine for relational data and structured data, It can construct and management for our high availability and high performance data applications.

2) To achieve flow control system

In the face of the network course teaching of teachers and students, the object is large, the flow control system is a key problem of stability and security to the network platform.

In the system, Internet information server can use IIS 7.0. The IIS7.0 web server can add or delete the module from the definition of the server, to meet the specific needs of the network platform, which is used for special function request handling. For example, IIS uses the cache module to manage the cache activity. IIS is a HTTP service and FTP server support. It supports flexible extensible modules to achieve powerful customization function, strengthen security by installing and running characteristics. IIS7.0 can also let those responsible for web applications or services in one of the people to the authorization and operation characteristics by selectively installed security enhancement.

3) Control of broadband traffic

With the development of $\mathrm{P} 2 \mathrm{P}$ end to end application development application, represented by BT has become the main part of the flow of network. Such applications are characterized by: a huge flow of communication, variety, no fixed service port, characteristic changes rapidly, difficult to detect. The traditional management of P2P application will face the following limitations:

(1) Blocking P2P port: On the one hand, rejected the request of user normal communication, reduce or in violation of the agreement. On the other hand, it led to the P2P application to use random and special port (HTTP port 80) to avoid detection.

(2) Use the NAT method to hide user public IP: It led to the wide application of NAT traversal techniques in P2P software.

(3) Blocking $\mathrm{P} 2 \mathrm{P}$ peer to the communication of $\mathrm{P} 2 \mathrm{P}$ information service node: Causes the P2P peer use proxy servers to avoid detection, also causes the $\mathrm{P} 2 \mathrm{P}$ information service node to random and hidden direction.

(4) Uplink bandwidth limit users: Violation of the treaty and lead to the network service user data requests to increase the amount of it.

In the problem of broadband traffic control in the network course platform, solution is HTTP traffic bandwidth management. To solve the $\mathrm{P} 2 \mathrm{P}$ flow management protocol analysis's difficulties, the depth of the protocol analysis is the final solution. The contents of the agreement of the flow control technology based on (Traffic Management by Application) and deep rate control technology (Deeper Kate Control) brings light to solve these problems. Compared with the ordinary optimization technology, several proprietary technology used in HTTP traffic bandwidth management series product has a significant characteristic. 
4) The implementation of concurrent user access system

The network curriculum development trend of multifunction, multimedia and interactive development, which put forward more requirements on the construction of network course platform. In the design of the system, there strengthen the concurrent user access requirements, implementation method and the algorithm of concurrent user access database development [3] .

Furthermore, meet the demand of "information technology and information management" course's characteristics in platform design, the network curriculum designs to outstanding the personalized learning and autonomous learning requirements. The course of network learning platform has the following characteristics:

"Information technology and information management" network course platform adopts some hypertext links providing to the student information and a lot of learning content. Application of navigation technology can give learners to design a good learning direction, to motivate students to learn, and provides effective learning [4]. Application of multimedia in the network course provides experience more aspects of visual and auditory senses. This also is the development trend of network course technology. Network curriculum construction in independent and individualized is learning to inspire students' enthusiasm for the course.

\section{Conclusion}

Learning network curriculum construction in independent and individual is favorable to inspire students' enthusiasm. It provides the network teaching environment, convenient and effective for the organization of Distance Education under the environment of teaching, which is also an inevitable trend in the information age of network course. The construction of effective network platform and the network teaching of" information technology and information management" course make it more enthusiasm, more effective in learning.

\section{References}

[1] Q. Zhong, Modern theory of curriculum, Shanghai: Shanghai Education Publishing House, 1998, pp.1-5

[2] J. Lin, S. Yu, "On the present situation and problems of network curriculum in China," The modern education technology, pp.51-55, January 2001.

[3] S. Sa, S. Wang, Introduction to database system, 3rd ed., Beijing: Higher Education Press, 2000, pp.440-455

[4] J. Wang, D. Yue, "Application of navigation technology in Network Course," Distance education in China, pp.54-55, January 2001. 